\title{
ESTUDIO SOCIO-SANITARIO EN POBLACIÓN INMIGRANTE MARROQUÍ
}

\author{
Isabel Gentil García*. \\ *Enfermera. Antropóloga. Profesora Titular E. U. Enfermería, Fisioterapia y Podología \\ Facultad de Medicina. Universidad Complutense de Madrid
}

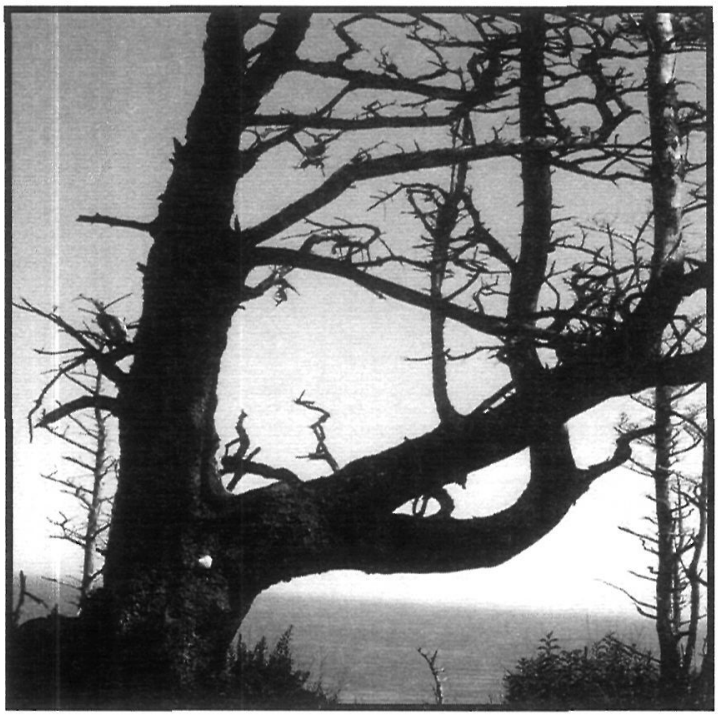

\section{ABSTRACT}

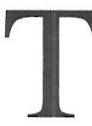
he increase of the immigration in Spain places us the professionals of enfermeria facing new challenges, for which we have little experience, as they are the to treat and interactuar with persons enculturadas in other cultures and with cosmovisiones different to ours. The objectives of this job are to achieve an approach al knowledge upon the perception, attitudes and beliefs relating to the health and the illness and to explore and to describe the particularities socioculturales, in adult immigrants of Morocco. The job of field was carried out in Majadahonda and Boadilla (Madrid), during the year 2001. The metodologia has been interviews in depth, individual. They went facts to 25 immigrants. The results indicate the great influence that the economic conditions and also the values socioculturales native have in the perceptions and practical related to the health and the illness.

\section{RESUMEN}

$\mathrm{E}$ 1 aumento de la inmigración en España nos coloca a los profesionales de enfermería frente a nuevos retos, para los cuales tenemos poca experiencia, como son el tratar e interactuar con personas enculturadas en otras culturas y con cosmovisiones diferentes a la nuestra. Los objetivos de este trabajo son lograr un acercamiento al conocimiento sobre la percepción, actitudes y creencias en relación a la salud y la enfermedad y explorar y describir las particularidades socioculturales, en inmigrantes adultos de Marruecos. El trabajo de campo se realizó en Majadahonda y Boadilla (Madrid), durante el año 2001. La metodología ha sido entrevistas en profundidad, individuales. Fueron hechas a 25 inmigrantes. Los resultados indican la gran influencia que las condiciones económicas y también los valores socioculturales indígenas tienen en las percepciones y prácticas relacionadas con la salud y la enfermedad.

\section{INTRODUCCIÓN}

La inmigración marroquí en España es reciente, a pesar de la cercanía geográfica y de los lazos históricos que unen a ambos países. El rápido crecimiento demográfico en Marruecos (pasó de 5 millones de habitantes al inicio del siglo XX, a 10 millones en 1954 y a 20 millones en la década de los ochenta, siendo en la actualidad de 2815 millones), sumado al alto índice de natalidad -aunque comienza a descender- que hace que su población sea extremadamente joven, casi la mitad es menor de 15 años, y unido a las grandes diferencias económicas y sociales que existen, favorece el flujo emigratorio.

En la actualidad el desarrollo económico a transformado España de país emisor de emigración a país receptor. España ha dejado de ser lugar de 
paso hacia Europa para el emigrante marroquí y se ha convertido en lugar de destino. La colonia marroquí pasa oficialmente de 16.665 en 1990, a 54.105 en 1992, y 65.847 en 1993 , en 1994 hay una ligera caída 63.939, un año después 1995 , la cifra asciende a 74.886. Según cifras del 2001, en la Comunidad de Madrid hay empadronados 42.551 marroquíes, más las personas pendientes de regularizar. Y la tendencia es a aumentar.

Los municipios de Majadahonda y Boadilla, donde se ha realizado el estudio, son lugares habituales de asentamientos de inmigrantes procedentes de Marruecos. Estos municipios están habitados por clases medias acomodadas, con urbanizaciones próximas de clases altas y zonas cercanas de gran actividad en la construcción, por las altas posibilidades de trabajo son zonas que tienen especial atracción para los inmigrantes.

Los profesionales de la salud nos encontramos frente a una nueva realidad para la que quizá estamos poco preparados: el interactuar con personas (sanas y enfermas) enculturadas en valores diferentes a los propios y con condicionantes económicos y sociales particulares.

\section{METODOLOGÍA}

Entrevistas en profundidad con inmigrantes adultos marroquíes y grupos de discusión, a lo largo del año 2001.

\section{RESULTADOS}

El trabajo de campo nos obliga a tener presente que no se puede hablar de "el inmigrante marroquî", como a veces se pretende, sino de los inmigrantes marroquíes, diferentes y diversos. Una diferencia es por razón de género, recordemos la marcada división de roles de género existente en su país de procedencia. Otra diferencia es por el motivo de migración, el económico es el más frecuente, pero no es el único, hay también motivos políticos y en personas jóvenes por "conocer mundo", "conocer Europa". Otra diferencia es la étnica, hay beréberes y árabes. Otra es el lugar de procedencia, los hay que proceden de zonas rurales aisladas y otros de ciudades tradicionalmente cosmopolitas como puede ser Tánger. Partiendo pues de la heterogeneidad de los inmigrantes marroquíes, trataremos de buscar las características más compartidas, las regularidades, como reflejo de su ser social, entendiendo que somos y nos hacemos en sociedad.

\section{Características familiares}

Podemos hacer tres modelos diferentes. El más frecuente: hombres solos, generalmente procedentes de aldeas rurales de montaña, del área del Rif, son beréberes con un sentimiento muy fuerte de serlo, se auto identifican diferentes de los árabes, cuya lengua algunos ignoran, son personas independientes, poco dadas a agruparse $\mathrm{u}$ organizarse en asociaciones, con tradición de emigrar, capaces de adaptarse a condiciones de vida y de trabajo muy duras, y con un objetivo claro: el ahorro económico. Otro modelo: algunos de esos hombres solos, pasado un tiempo, y si las condiciones económicas y sociales lo permiten traerán a otros miembros de su familia. Si están casados: primero los hijos varones mayores, después a los hijos pequeños y a la esposa. Si están solteros a hermanos, primos, tíos. Por último, mujeres, generalmente solteras, pero también divorciadas, separadas y en algún caso casadas, trabajando en el servicio doméstico, lo más habitual internas.

\section{Actitudes ante la enfermedad.}

La causa de enfermedad reconocida más frecuente es el pasar frío, "la gente se pone mala de frío sobre todo", quizá sea éste uno de los motivos por los que van tan abrigados, también porque a veces comparten la misma vivienda con gran número de personas: unas conocidas, otras desconocidas y prefieren llevar sus pertenencias encima. De enfermedades, la más conocida es la pulmonía, y piensan que esta enfermedad se produce por pasar frío.

Ante la enfermedad su actitud es la de paciencia. Las frases ,"es porque Dios quiere que sea asî", "está escrito", son utilizadas con frecuencia en sus conversaciones en relación con la enfermedad. Si la enfermedad la consideran banal, paciencia es la palabra repetida, "ante la enfermedad hay que tener paciencia, paciencia, y ya se pasará y si no se va a pasar ¿por qué gastar en medicinas?”. Pero la paciencia es una actitud que se mantiene también, ante la enfermedad grave: "cuando la persona está enferma de verdad, no se puede hacer nada, no se 
puede hacer nada: paciencia". Por esto difícilmente acudirán a consulta para actuaciones preventivas de diagnóstico precoz. Al contrario les llama la atención las prisas que mostramos los españoles para acudir al médico, hay veces que hasta les resulta jocoso por lo que para ellos es exagerado en nosotros, esa prisa por ir al médico ante cualquier cosa, "siempre los marroquíes esperan para ir al médico, los que van pronto son ustedes, por ejemplo, no tienen paciencia como nosotros, nosotros esperamos, no vamos deprisa al médico como vosotros". Cuando les explico los motivos que tenemos para acudir pronto, intentando con ello trasmitir el concepto de diagnóstico precoz y les digo: "nosotros pensamos que cuanto antes vayamos, antes nos vamos a curar", se quedan pensando y dicen: "claro, está bien eso, pero nosotros es que no es nuestro país, somos inmigrantes, se puede quedar así malo uno, treinta días..., meses."

La fiebre no es motivo, en general, para consultar, "se va al médico cuando se está muy mal, por ejemplo si sólo fiebre, no se va al médico, eso se pasa solo". "¿Y si no se pasa solo?" -pregunto, "si no se pasa después de muchos días, si se va, si eres legal, pero si no lo eres, no vas. Sin papeles no se puede ir al médico, ¿tu entiendes?". "Y ¿si hay tos?". "Si hay tos se aguanta".

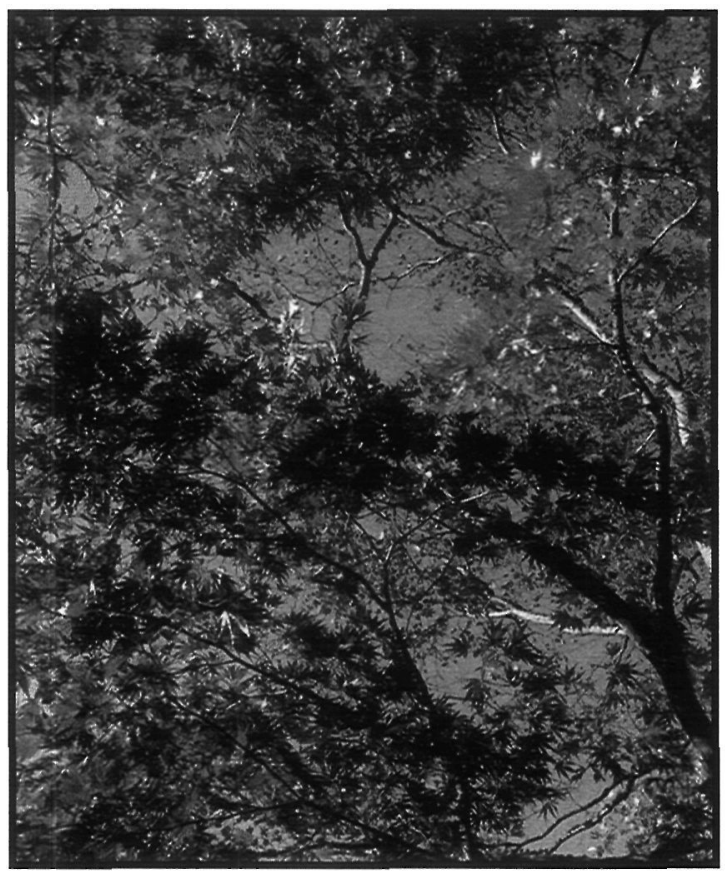

El prestar poca importancia a los síntomas o manifestaciones del cuerpo no se produce en los casos que hay dolor que impide trabajar. Los dolores más frecuentes: de espalda, de muelas y de estómago, por este orden. De hecho acuden con periodicidad a la farmacia a por pastillas para el dolor, y esto es así para poder seguir funcionando. Es el mismo motivo que les lleva a no escuchar o prestar poca atención a otros síntomas de enfermedad en sus cuerpos. Es porque el objetivo fundamental, para ellos, es el rendimiento económico de su cuerpo como fuerza de trabajo.

Existe un sentimiento de solidaridad para con la persona enferma, "lo dice Dios", cuando hay una persona enferma se reza por ella, a nivel individual, pero sobre todo de forma colectiva para pedir a Dios por su salud: "las personas cuando están enfermos le piden a Dios". "Si hay uno enfermo toda la gente pide en la mezquita por el que está enfermo, cuando terminan de rezar en la mezquita, todos hacen así con las manos a Dios, todos, dicen este señor, pobrecillo, por este que está enfermo".

Hay que recordar que existe una práctica higiénica muy asumida, el lavado de las manos, sobre todo antes de comer, "porque lo dice el Corán", y les llama poderosamente la atención ver que españoles comen tocando los alimentos con las manos sin haberlas lavado previamente, "yo he visto aquí gente comer una fruta, un bocadillo con las manos sucias".

\section{A quién acuden en caso de enfermedad.}

Ante la enfermedad la primera premisa es la paciencia y esperar, después, si tienen trabajo y Tarjeta Sanitaria, al médico que les corresponde, las palabras "tarjeta de la seguridad social", por poco vocabulario de español que tengan, la saben decir prácticamente todos. Los que no tienen los papeles en regla, por lo general, si suelen tener información sobre qué instituciones atienden sin pedir papeles, "la gente que no está legal, va al Ayuntamiento, Cruz Roja y así, allí no piden papeles, no piden carta de Seguridad Social." Hay que tener en cuenta que los inmigrantes con los que se han tenido las conversaciones son personas que están acudiendo a un Centro de voluntariado social, es decir personas que tienen un cierto nivel de inquietud, de saber buscar soluciones y de saber 
defenderse. Aunque también es cierto que las personas que acuden al Centro son siempre personas necesitadas, uno de ellos me dice: "La gente que tiene trabajo y dinero no viene a este Centro."

El comportamiento de los hombres, y más de las mujeres, ante la exploración física es de pudor cuando tienen que mostrar el cuerpo. Por otra parte son los inmigrantes jóvenes los que aceptan con más facilidad ciertas medidas diagnósticas que los inmigrantes de mayor edad, quizá sus expectativas de mejorar están más activas que en los inmigrantes mayores.

A pesar de estar informados sobre donde acudir en caso de enfermedad, si no tienen "papeles" prefieren no acudir, a no ser que se vean obligados por la gravedad, "pero si no son legales ¿sabes? tienen miedo de la policía, no se pueden arriesgar a ir ¿sabes?, a personas como L. y así, que ayudan mucho a los inmigrantes si, pero si no ¿tu sabes? tienen miedo". Los inmigrantes sin regularizar los documentos saben que viven en el filo de la navaja, y tienen muy asumido que si pasan desapercibidos no tendrán problemas, su mejor manera de sobrevivir es no significándose en nada y una forma de significarse puede ser acudiendo a una institución sanitaria. Los inmigrantes sin papeles en regla, colocan ante sí una barrera tanto física como de silencio. Tienen muy claro que su supervivencia en su condición de indocumentados depende de no emitir sensaciones, ni visuales, ni sonoras. "Si no te metes en problemas la policía no te dice nada", por ello el indocumentado irá a solicitar ayuda sanitaria en casos de extrema gravedad.

\section{Dificultades para acudir a consulta}

Además del miedo, en los casos de personas sin documentación regularizada, existen otros motivos. Un factor que dificulta el que acudan es la pérdida de la jornada de trabajo. Realizan largas jornadas laborales, están en los trabajos de nueve de la mañana a siete de la tarde y no les resulta fácil solicitar permiso, sabiendo que cuando les toque renovar el permiso de residencia, generalmente una vez cada año, la burocracia con sus cupos de atención diaria y con sus largas colas, les obligará a perder tres, cuatro, o más jornadas de trabajo. Además el tipo de trabajos que realizan: en la construcción, jardinería, "chapuzas", significa que el lugar del trabajo está lejos de los Centros de Salud. Suelen trabajar en urbanizaciones fuera del pueblo o en zonas de nuevas edificaciones, el desplazamiento para ir a consulta, supone acudir a solicitar cita previa, luego acudir a la hora citada y allí esperar, es decir pérdida de una jornada de trabajo. "Yo voy a un médico porque ese médico no me pide la cita y me ve cuando voy". Además muchos de ellos trabajan en pequeñas empresas donde el solicitar un permiso por ausencia para ir al médico se vive más como un favor personal del jefe, que como un derecho. Otros trabajan por "acuerdos", o a temporadas dependiendo de las demandas laborales y ellos saben lo importante que es estar presente y "cumplir" cuando se les oferta un trabajo temporal, pues de la cantidad de confianza y buen hacer profesional que sean capaces de demostrar, dependerán las futuras solicitudes para trabajar, "a mi nunca me falta trabajo, porque los jefes saben que soy hombre de confianza y cumplo y siempre dicen H. que venga $H . "$

\section{Actitudes ante los tratamientos}

Hay un rechazo generalizado hacia las medicinas de farmacia, cuando se les pregunta por qué, dicen que son malas, llevan "química". Excepto en los casos de dolor, como ya apuntamos. En general hay un rechazo grande a los productos que lleven "química", ya sea en referencia al agua, "mejor la natural, la que corre", ya sea en relación a la comida, "los pollos para comer si son naturales del campo, naturales, son buenos pero si son alimentados con química son malos". Sin embargo hay un gran respeto por lo que ellos llaman "medicina natural", a base de plantas, sobre lo cual es difícil profundizar. Parece que existe una tradición de conocimientos de plantas medicinales que pasa a través de las mujeres: "Las mujeres todas saben de plantas, antiguamente donde mis abuelos, mis padres, no estaba el médico, estaba muy lejos, para verle tienes que coger un autobús a doscientos, trescientos kilómetros, ellas saben, de libros también, ellas se lo dicen y van a la montaña a por hierbas, todo natural, lo que da la tierra". Además en Marruecos las personas acuden a los mercadillos donde existen especialistas en tratamientos con plantas: "en los mercadillos hay gente que sabe y tiene tiendas de cosas naturales, todo natural, no 
compras en farmacia nada, y si no tienes dinero da igual, te dan la cosa natural gratis".

En su país, en estos momentos están conviviendo dos modelos de medicina: la natural, por plantas, masajes, aceites, y que se está perdiendo. Antes existía un conocimiento empírico, en ciertas personas, para tratar problemas de huesos que en la actualidad también se está perdiendo. "Mi padre trataba los huesos enfermos, hasta las fracturas, aprendía con los huesos de las cabras, pero ahora ya no se sabe de eso porque ahora hay médicos y hay coches, antes no había médicos ni coches, y teníamos que saber nosotros de curar". Por otra parte la medicina occidental, que es cara y de difícil acceso, no hay cobertura de asistencia médica estatal. Aunque en gente joven hay una tendencia hacia la búsqueda de soluciones en caso de enfermedad mediante la consulta a la medicina occidental, sin embargo las dificultades económicas impiden que la mayoría de las personas puedan estar atendidas. A la vez se está produciendo la pérdida de interés en personas jóvenes por aprender los saberes de la medicina tradicional: "Antes en Marruecos se curaban con plantas, pero ahora en Marruecos ya no quedan personas que sepan de plantas y los médicos que hay son pocos y caros, solo quieren que gastes dinero en medicinas, así que ahora allí no tenemos ni las plantas ni al médico". Existían también ciertas creencias tradicionales para prevenir la enfermedad, donde se combina el éxito en la prevención con la práctica de limosna a personas pobres. "Mi madre cuelga dinero en el techo de la casa, tanto por cada hijo y ese año el hijo no coge enfermedad de garganta, pasado el año ese dinero se da a los que no tienen. El año que no pone el dinero enfermamos de la garganta".

Con la pérdida de saberes tradicionales se esta perdiendo precisamente, el conocimiento empírico, el elaborado, el de curación por el uso de plantas, se está perdiendo el conocimiento que requiere un gran tiempo de aprendizaje y que necesita del contacto prolongado entre el veterano experto conocedor y el aprendiz y está perdurando sólo el de la creencia, el del rito, el externo, el que no necesita ese periodo de aprendizaje, el que se puede recrear en cada actuación y sin consecuencias.

Parece que algunos traen plantas de Marruecos para sus tratamientos pero profundizar sobre este tema es muy difícil. "Cuando duele el estómago no se va al médico, si hay algo de hierba en la casa, se toma". Hay rechazo a hablar sobre ello. Es un tema tabú para hablar con extraños. Quizá teman manifestar estos conocimientos y dar con ello una imagen de "primitivos" ante los españoles, sabiéndonos orgullosos de nuestra medicina científica altamente tecnificada y además, como ciertas medidas terapéuticas empíricas están devaluadas en nuestra cultura occidental, sobre todo si quienes las utilizan son personas procedentes de países con niveles de pobreza mayores que el nuestro, su respuesta sea el silencio y el ocultamiento. Quizá esos conocimientos empíricos de curación por plantas sean para ellos, señas de identidad muy fuertes y no aptas para ser comunicadas a alguien de fuera.

El rechazo a las medicinas de farmacia influye también en el cumplimiento de tratamientos prolongados, se inicia el tratamiento médico pero en cuanto notan mejoría se abandona: "las pastillas que mandan, si con un día te sale bien la enfermedad ya no se siguen tomando, ¿por qué tomar química?".

Sin embargo sí se acude a las medicinas de la farmacia, cuando hay dolor agudo, como se comentó anteriormente, "si hay dolor se va a la farmacia a comprar algo". "Sólo cuando hay dolor se toman pastilla calmante de farmacia". Es decir acuden a la farmacia cuando tienen un problema de salud que realmente les impide funcionar. Son personas que tiene muy claro la importancia de "cumplir" con el trabajo, por ello es para la sintomatología que les pueda impedir o dificultar la realización de su trabajo para la que buscarán soluciones, a ser posible inmediatas y sin burocracias. Acuden a la farmacia, relatan su dolencia y la farmacia les da el remedio. Es el modelo más parecido al vendedor de plantas del mercadillo. En la medicina que ellos llaman natural, la tradicional por plantas, la persona que se siente enferma acude a consultar al experto, quién le diagnóstica y a la vez y en el momento le da el remedio. En España se encuentra con una disociación médico/farmacéutico. El médico sabe de enfermedades pero no da el remedio: el medicamento. Esta función la deriva a la farmacia y además la atención médica está burocratizada, recordemos que sienten rechazo por el 
uso y abuso de los papeles a que se somete al inmigrante, y aquí el médico despacha papeles: recetas, volantes etc. pero no la medicina, el remedio. El médico no les soluciona realmente su problema de enfermedad, se lo complica aún más con papeles. Las recetas (papeles) derivan al farmacéutico y este cobra dinero por la medicina, luego el médico es gratis, si, pero no resuelve y deriva a otro, que resuelve, al cual hay que pagar.

El problema del gasto económico en medicinas es otro factor de rechazo hacia las mismas, "al médico se va poco, se va cuando uno está muy mal, el médico no es para ir mucho, manda muchas medicinas y hay que gastar mucho dinero, el medico manda gastar dinero y luego no te curas, ¿por qué hacen gastar en medicinas si luego no se cura?". Recordemos que una gran parte de la inmigración lo hace por motivos económicos, y el ahorro de dinero es un objetivo fundamental. Los motivos de ahorro pueden ser diversos, mandar dinero a la familia, "aquí con tres mil pesetas no vive mi familia, pero yo mando esas tres mil pesetas a Marruecos y allí pueden vivir todos", o para construirse una vivienda en Marruecos, o para traerse a la familia y quedarse en España, pero en todos los casos exige el control del gasto económico y este control pasa por restringir el gasto. Los tipos de trabajo que realizan, construcción, servicio doméstico, chapuzas, hacen que fluctúen las demandas para trabajar, lo que supone una situación añadida de inestabilidad y riesgo económico. La amenaza de no renovación de los permisos de trabajo es una constante.

Quizá por el rechazo a las medicinas de farmacia hay simpatía hacia los médicos que no se limitan a dar una receta, "me corresponde por los papeles una médica muy buena, no manda muchas medicinas, dice qué cosas hay que hacer, eso está mejor que las medicinas, he pedido que siempre me dejen esa médica y si es esa médica si es bueno ir al médico".

\section{Proceso de reformulación de su identidad}

Los emigrantes al tener que enfrentarse a otras formas de vida les lleva a una reformulación de su propia identidad. Los inmigrantes marroquíes están inmersos en un proceso de transformación identitaria, encontrándose muchas veces, en una "tierra de nadie". Ciertas costumbres tradicionales pierden fuerza pero a la vez pesa mucho el referente tradicional. Las distintas formas de identidad vienen dadas por las distinciones que cada cultura moldea como significativas para ordenar el mundo y clasificar a las personas.

$\mathrm{El}$ inmigrante al enfrentarse con otra realidad social y cultural, puede reaccionar de tres maneras. Una, reforzando su propia identidad a través de enfatizar lo que es considerado socialmente como señas de identidad de su propia cultura, pero es el grupo de los otros, el de las personas del país de acogida, quienes les dicen cuales deben ser sus señas de identidad aquí, y ellos lo reciben como: lo que me identifica en este país como musulmán es esto, luego para significarme musulmán frente a los autóctonos son estos los signos que debo mostrar, no tanto para mí sino para que el otro pueda reconocerme como tal. Se construye la identidad recogiendo el reflejo del espejo que muestra la imagen que tenemos construida del musulmán. En este caso cierta identidad musulmana se crea, o se significa especialmente en España, quizá para remarcar la diferencia, como reacción, es la respuesta a: puesto que no pueden ser totalmente iguales, al menos ser totalmente diferentes. "Cuando tenía 16, 17, 18 años yo bebía cerveza, pasaba con los amigos a Ceuta y allí bebíamos." ¿Y Ahora?, pregunto- "No, yo aquí soy musulmano". Entendiendo el ser musulmán no tanto la práctica de una religión, como el adscribirse a un grupo cultural, que sin embargo si toma de referencia para comportamientos lo que dice el Corán, "lo dice el Corán", respuesta frecuente a preguntas sobre conductas. Aunque el Islam dicte normas para muchos comportamientos cotidianos, parece que la frecuencia de uso de la respuesta "Dios así lo dice", busca evitar entrar en discusión, o como justificante. Definirse como musulmán supone poner distancia con las costumbres y tradiciones encontradas en el país de acogida.

Otra: rechazando las características que socialmente se atribuyen a su grupo y cultura, en este caso enfatizando los usos y signos externos de la sociedad de acogida. Como lo más fácil es imitar lo externo, en algunas personas jóvenes es la adopción de ciertas formas de vestir: ropa deportiva que recuerda a cualquier adolescente de EE.UU. 
Otra: en un sincretismo de valores, muchas veces después de pasar por periodos donde ha habido fluctuación de uno a otro de los modelos anteriores, con avances y retrocesos entre uno $\mathrm{u}$ otro modelo, se llega a asumir como propios valores de la sociedad de acogida, sin renunciar a valores procedentes de su propia cultura de origen. Este proceso no es sencillo, no es una mezcla proporcionada de partes, no es una suma: valores de una cultura mas valores de otra cultura, igual a. Se vive muchas veces como ruptura con valores previos y sobre todo como contradicción, no renunciando a su identidad o definición como musulmanes, aunque la práctica religiosa esté abandonada, no así la práctica del Ramadán, quizá porque esto les refuerza su identidad primigenia, impidiéndoles caer en un vacío de indefinición. Se siguen considerando musulmanes como pilar inamovible y a partir de ese principio sustentador aceptan y asumen valores de la sociedad de acogida, por ejemplo: la democracia y la libertad, dos de las características más valoradas.

\section{CONCLUSIÓN}

Al relacionarnos con inmigrantes marroquíes habrá que tener presente: $1^{\circ}$. Sus dificultades de comunicación, bien por desconocimiento del idioma, bien por desconocimiento de los códigos de comunicación diferentes a los de su país de procedencia, bien por temor a significarse si no tienen papeles. $2^{\circ}$. El proceder de otra cultura donde se da un gran valor a las plantas como terapéutica y un rechazo a las medicinas de "química". $3^{\circ}$. Las dificultades diarias para acudir al médico, trabajan en jornadas prolongadas y alejados de los centros geográficos donde se encuentran los Centros de Salud. $4^{\circ}$. Las condiciones precarias de trabajo, que les obliga a no consultar un problema de salud si en esos momentos tienen trabajo. $5^{\circ}$. Las condiciones de fragilidad socioeconómicas de estas personas. Uno de sus objetivos principales es el ahorrar dinero, esto siempre obliga a dar más importancia al trabajo que a la salud, cuando deben de ponerse en una jerarquía de elección por prioridades. $6^{\circ}$. Que son personas que han realizado un largo viaje (físico, emocional, etc.) para mejorar sus condiciones económicas y sociales, lo que significa que son personas con intereses claros por cuidar y mejorar su salud, si las circunstancias se lo permitiesen, si las restricciones y las trabas arriba apuntadas mejorasen.

Quizá la educación, sensibilizando a todos los colectivos involucrados, (inmigrantes, profesionales de la salud) sea la herramienta para que por todos los lados se pueda caminar hacia el mismo objetivo, esto es, mejorar la salud de todos los ciudadanos que compartimos el mismo territorio para vivir, seamos nacidos aquí o en cualquier otro lugar. Habrá que tomar conciencia que las sociedades occidentales tienden a ser cada vez más sociedades multiétnicas. La riqueza multicultural se basa en reconocer las distintas formas culturales y en crear situaciones de intercambio mutuo, no es anular una cultura por imposición de valores procedentes de la más desarrollada tecnológicamente, sino todo lo contrario, conocerla para establecer comunicación entre iguales. No exigencia de "nosotros" conocedores a "ellos" ignorantes. No buscar la asimilación del inmigrante con pérdida de sus valores culturales, ni pretender el inmigrante perpetuarse en la absoluta diferencia nostálgica.

\section{BIBLIOGRAFÍA}

- Delgado, J.M. y Gutierrez, J. (1994) Métodos y Técnicas cualitativas de investigación en ciencias sociales". Síntesis, Madrid.

- Goffman, E. (1970) Estigma, la identidad deteriorada. Amorrortu, Buenos Aires.

- Morales, V. (1993) Inmigración africana en Madrid. Uned, Madrid. 